Revista Brasileira de Cartografia

ISSN 1808-0936 | https://doi.org/10.14393/revbrascartogr

Sociedade Brasileira de Cartografia, Geodésia, Fotogrametria e Sensoriamento Remoto

\title{
Características Técnicas do Cadastro Territorial Temático de Sítios Arqueológicos Brasileiros
}

\section{Technical Characteristics of Brazilian Thematic Cadaster of Archaeological Sites}

Guilherme Linheira ${ }^{1}$, Francisco Henrique de Oliveira²

1 Universidade do Estado de Santa Catarina, Departamento de Geografia, Florianópolis, Brasil. E-mail: glinheira@ hotmail.com. ORCID: https://orcid.org/0000-0002-4416-9938

2 Universidade do Estado de Santa Catarina, Departamento de Geografia, Florianópolis, Brasil. E-mail: chico.udesc@gmail.com. ORCID: https://orcid.org/0000-0002-6913-3261

Resumo: Os cadastros territoriais consistem em inventários públicos de dados diretamente relacionados à representação gráfica das parcelas e dos objetos territoriais. De modo complementar à geração do banco de dados do cadastro há a necessidade da caracterização jurídica da feição territorial representada (parcela ou objeto territorial). $\mathrm{O}$ objeto territorial é definido como uma porção de terra com condições homogêneas em seus limites, em função de sua finalidade. Portanto, todo elemento natural, artificial ou restritivo por legislação sobre o solo - tais como cursos d'água, áreas de conservação ambiental, e ainda os sítios arqueológicos potencialmente se enquadram como objeto territorial. A identificação e mapeamento destes elementos requisitam um conhecimento específico, mobilizando a participação de instituições especializadas, configurando os chamados cadastros territoriais temáticos. Sendo assim, o presente artigo apresenta como foco de estudo o Cadastro Nacional de Sítios Arqueológicos - CNSA. O CNSA é o sistema cadastral que contém as informações espaciais dos sítios arqueológicos localizados no território brasileiro, apresentando atualmente cerca de 27 mil registros, sendo gerenciado pelo Instituto do Patrimônio Histórico e Artístico Nacional - IPHAN. Neste contexto, o artigo caracteriza e analisa as características técnicas do cadastro temático vinculado aos sítios arqueológicos. Como resultado, destaca-se que o CNSA apresenta fragilidades com relação ao rigor no processo de medição geométrica de seus limites ao não estabelecer critérios mínimos e padronização técnica no referido processo. Dessa forma, gera incertezas e consequentemente inseguranças jurídicas no posterior uso destes dados.

Palavras-chave: Cadastro Territorial Temático. Cadastro Nacional de Sítios Arqueológicos. Sítios Arqueológicos.

\begin{abstract}
Territorial cadastres consist of public inventories of data related to the graphic representation of parcels and territorial objects. Complementarily to the generation of the cadastral database, there is a need for the legal characterization of the represented territorial feature represented by parcel or territorial object. The territorial object is defined as a portion of land with homogeneous conditions at its limits, according to its purpose. Therefore, any natural element, artificial or restrictive by legislation on the land - such as water courses, areas of environmental conservation, and even archaeological sites potentially fit as a territorial object. The identification and mapping of these elements requires specific knowledge, mobilizing the participation of specialized institutions, configuring the so-called thematic territorial cadasters. Thus, the present article focuses on the National Register of Archaeological Sites - CNSA. The CNSA is the cadastral system that contains the spatial information of the archaeological sites located in the Brazilian territory, currently presenting about 27 thousand records, being managed by the National Historical and Artistic Heritage Institute - IPHAN. In this context, the article characterizes and analyzes on technical way the thematic cadaster linked to archaeological sites. As a result, it is notorious that the CNSA has weaknesses in the process of geometric measurement considering its limits by not establishing minimum criteria and technical standardization in the referred process. Thus generate cartographic uncertainties representation and consequently legal insecurities in subsequent use of this data.
\end{abstract}

Keywords: Thematic Territorial Cadaster. National Archaeological Sites Cadaster. Archaeological Sites 


\section{INTRODUÇÃO}

A história da sociedade humana no planeta tem sido regida pela sua relação com o espaço geográfico. O reconhecimento da localização e características dos diversos elementos que compõe o espaço permitiu que a sociedade atuasse sobre ele, transformando-o de forma significativa. Nesse contexto, os mapas surgiram como importantes ferramentas para materializar o conhecimento da localização de objetos e fenômenos geográficos. Registros históricos como os mapas de Bedolina (2.500 a.C.) e de Ga-Sur (2.200 a.C) indicam que as primeiras tentativas de organização e representação de dados espaciais datam do período histórico designado como Idade Antiga, evidenciando, portanto, a importância das representações espaciais para a sociedade (MARTINELLI; GRAÇA, 2015).

Ainda na Idade Antiga, povos como egípcios e babilônicos utilizaram dados espaciais para nortear a cobrança de tributos, a identificação dos direitos de propriedade e a garantia e segurança do comércio de terras. Com o decorrer dos períodos históricos novas técnicas e tecnologias foram desenvolvidas, havendo, concomitantemente, a ampliação dos usos dos dados que eram coletados. Embora esse processo de medição e registro de terras tenha evoluído no decorrer do tempo, a ideia primordial permaneceu: medir e caracterizar as diversas parcelas e objetos que existem em um determinado território. Tal processo adquiriu tamanha relevância no decorrer da História que consolidou na Idade Contemporânea um ramo de estudos específicos da ciência cartográfica, denominado de Cartografia Cadastral. Os produtos gerados no âmbito desse ramo, por sua vez, passaram a ser designados como cadastros territoriais (LOCH, 2001).

Ainda que tenham sido utilizados inicialmente para questões jurídicas e tributárias, as informações compiladas pelos cadastros territoriais passaram a ser gradativamente utilizadas para outros fins como o planejamento territorial e ambiental. Por este motivo, frequentemente os cadastros têm sido referenciados pelo termo cadastro territorial multifinalitário. No contexto histórico contemporâneo, a Federação Internacional dos Geômetras (FIG) define o cadastro territorial como um inventário público dados de todas as parcelas e objetos territoriais legais, sejam eles públicos ou privados, existentes em um determinado território baseado na agrimensura de seus limites. Os cadastros territoriais, além de conter dados dos limites físicos, apresentam também uma série de dados descritivos capazes de indicar a natureza, o tamanho, o valor e os direitos ou restrições legais que eventualmente incidem nestas parcelas e objetos (KAUFMANN; STEUDLER, 1998).

Essa concepção contemporânea acerca dos cadastros territoriais supera os antigos paradigmas imobiliário e parcelário visto que prevê o cadastramento de todo e qualquer elemento que se materialize na superfície terrestre e que apresenta um enquadramento jurídico específico. Como exemplo dessa situação, citase, além dos bens imobiliários, a necessidade de cadastramento de linhas de transmissão de energia elétrica, de cursos d'água, de áreas de conservação ambiental, de sítios arqueológicos, dentre outros. Em muitos casos, estes elementos apresentam regimes jurídicos protetivos, ou seja, são dotados de algum tipo de proteção por força de lei. Neste caso, os cadastros territoriais constituem as ferramentas que congregam todas essas informações, possibilitando a apreensão da realidade espacial por parte do poder público, subsidiando as ações vinculadas aos processos de planejamento e gestão territorial principalmente na escala municipal.

Dentre os elementos que se materializam em um território existem aqueles que apresentam tantas particularidades que sua identificação e mapeamento requisitam um conhecimento específico, mobilizando a participação de instituições que detenham tal expertise. Nestes casos, cabe a estas instituições a criação de cadastros territoriais específicos, caracterizando os chamados cadastros territoriais temáticos. Suas informações devem suplementar o cadastro territorial, de modo que este consiga, de fato, contemplar toda a superfície de um território.

No caso do Brasil, as prefeituras tem reconhecido a importância dos cadastros territoriais nos processos de planejamento e gestão territorial e vem se empenhando na criação e manutenção de seus bancos de dados geoespaciais. Paralelamente, existem no Brasil diversos cadastros territoriais temáticos que são gerenciados pelas instituições responsáveis por cada um destes temas. Como exemplo, citam-se o cadastro territorial de caráter fiscal, mantido pela Receita Federal, os cadastros ambientais mantidos pelo Instituto Nacional de Colonização e Reforma Agrária (INCRA) e pelo Ministério do Meio Ambiente, o cadastro de unidades de conservação mantido pelo Instituto Chico Mendes de Conservação da Biodiversidade (ICMbio) e o cadastro 
de sítios arqueológicos gerenciado pelo Instituto do Patrimônio Histórico e Artístico Nacional (IPHAN). É exatamente sobre este último exemplo que o presente artigo direciona seu foco. A opção de abordar o cadastro temático de sítios arqueológicos decorre, em primeiro lugar, da reconhecida relevância destes locais para a ciência, e, em segundo lugar, da exígua produção técnica-científica sobre este cadastro.

De maneira introdutória, destaca-se que os sítios arqueológicos definem-se como locais onde podem ser encontrados os remanescentes materiais de populações pretéritas. Em muitos casos, esses vestígios materiais constituem a única fonte de informação dessas populações, auxiliando, portanto, na reconstrução da história dos seres humanos no planeta. No Brasil os sítios arqueológicos são considerados bens da União e protegidos por uma série de diplomas legais. É importante ressaltar que reconhecimento da importância sobre os sítios arqueológicos e outros bens patrimoniais é resultado de longos processos de discussão técnica internacional sobre o tema. Nesse sentido, o Brasil tem buscado um alinhamento com os imperativos de proteção dos bens patrimoniais, criando leis e instrumentos visando essa salvaguarda. Internacionalmente, a Organização das Nações Unidas para Educação, Ciência e Cultura (UNESCO), criada em 1942, tem se destacado na liderança da produção de uma série de documentos técnicos, como Cartas, Recomendações, Declarações e Normas que tem como objetivo básico o destaque do valor dos bens culturais e a elaboração de diretrizes para efetivação de proteção pelos países signatários, dos quais o Brasil faz parte.

Visando realizar a gestão dos sítios arqueológicos existentes em território nacional, o IPHAN mantém o Cadastro Nacional de Sítios Arqueológicos - CNSA que apresenta atualmente cerca de 27 mil sítios registrados. O CNSA é a principal ferramenta que o poder público e a sociedade civil dispõem para reconhecimento da existência e localização desse tipo de bem patrimonial possibilitando que os entes federados possam cumprir as obrigações legais de preservação destes locais. Dessa forma, o objetivo do presente artigo é descrever as características técnicas, isto é, a lógica de organização de dados espaciais e alfanuméricos do Cadastro Nacional de Sítios Arqueológicos, confrontando-os com os pressupostos teóricos da Cartografia Cadastral. Para atingir tais objetivos foram realizadas revisão bibliográfica e análise documental da legislação e de documentos técnicos que balizam o tema no país.

\section{CADASTROS TERRITORIAIS NO BRASIL}

Embora alguns países como Alemanha e Holanda tenham uma "cultura cadastral" secular, no Brasil as primeiras iniciativas datam apenas da década de 1960. Essa inciativa inicial apresenta forte relação com a promulgação da Constituição Federal de 1946 que possibilitou maior autonomia aos municípios brasileiros, permitindo a partir daquele momento que iniciassem a cobrança de tributos referente à ocupação de seu território. Ainda neste contexto, o governo federal criou em 1964 o Serviço Federal da Habitação e Urbanismo (SERFHAU) que tinha como objetivo planejar e executar as políticas de desenvolvimento urbano no país e que financiou projetos de cadastro territorial em algumas cidades grandes e médias (LOCH, 2001).

Em 1977, outra iniciativa federal beneficiou o desenvolvimento do cadastro territorial urbano dos municípios brasileiros. Dessa vez a iniciativa teve origem no Serviço de Processamento de Dados (SERPRO) que lançou o Convênio de Incentivo ao Aperfeiçoamento Técnico-Administrativo das Pequenas Municipalidades (CIATA). Diferentemente da iniciativa anterior promovida pelo SERFHAU, o CIATA foi destinado aos pequenos municípios brasileiros, que à época apresentavam déficit na arrecadação por, dentre outras situações, apresentarem defasagem cadastral quando comparados aos municípios de porte médio e grande que foram beneficiados pelo programa anterior ( $\mathrm{LOCH}, 2001)$.

As iniciativas do governo federal restringiram-se a oferta de financiamentos para que os municípios pudessem estruturar os cadastros territoriais de suas áreas urbanas. Não foi criada à época nenhum tipo de legislação ou orientações que indicassem os parâmetros técnicos e conceituais a serem utilizados. Assim, o desenvolvimento dos cadastros territoriais urbanos no país seguiu caracterizado por iniciativas tecnicamente isoladas. A mesma realidade aconteceu com as instituições públicas nacionais que produziam e que os organizavam seus dados espaciais a partir de lógicas específicas. Como resultado, criou-se no Brasil uma série de entraves para integrar dados geoespaciais oriundos de fontes distintas.

A ausência de modelos padronizados para organização de dados geoespaciais perdurou até o ano de 2008. Neste caso, diante das dificuldades e do crescente volume de produção de dados geoespaciais, o Estado 
brasileiro publicou o Decreto $n^{\circ}$ 6666/08 que instituiu a Infraestrutura Nacional de Dados Espaciais (INDE). Em linhas gerais, o diploma criou "um ordenamento na geração, no armazenamento, no acesso, no compartilhamento, na disseminação e no uso dos dados geoespaciais de origem federal, estadual, distrital e municipal, em proveito do desenvolvimento do país" (BRASIL, 2008, p. 1). Em outras palavras, a INDE consistiu na adoção de um conjunto de normas e padrões comuns para permitir e facilitar o compartilhamento interinstitucional de dados geoespaciais.

Do Decreto $n^{\circ}$ 6666/2008 destaca-se o inciso I do artigo $2^{\circ}$, que conceitua dado geoespacial como "aquele que se distingue essencialmente pela componente espacial, que associa a cada entidade ou fenômeno uma localização na Terra, traduzida por sistema geodésico de referência". De forma complementar, o inciso II definiu metadado como o "conjunto de informações descritivas sobre os dados, incluindo as características do seu levantamento, produção, qualidade e estrutura de armazenamento, essenciais para promover a sua documentação, integração e disponibilização, bem como possibilitar a sua busca e exploração" (BRASIL, 2008, p.1).

Ainda tratando do Decreto $n^{\circ}$ 6666/2008, o artigo $2^{\circ}$ conceituou no inciso III a Infraestrutura Nacional de Dados Espaciais - INDE como "o conjunto integrado de tecnologias; políticas; mecanismos e procedimentos de coordenação e monitoramento; padrões e acordos, necessário para facilitar e ordenar a geração, o armazenamento, o acesso, o compartilhamento, a disseminação e o uso dos dados geoespaciais de origem federal, estadual, distrital e municipal" (BRASIL, 2008). Do mesmo artigo, destaca-se ainda o parágrafo $2^{\circ}$ do inciso V: "Serão considerados dados geoespaciais oficiais aqueles homologados pelos órgãos competentes da administração pública federal, e que estejam em conformidade com o inciso I do caput" (BRASIL, 2008, p.1).

Por fim, destaca-se ainda o artigo $3^{\circ}$ que definiu que o "compartilhamento e disseminação dos dados geoespaciais e seus metadados é obrigatório para todos os órgãos e entidades do Poder Executivo federal e voluntário para os órgãos e entidades dos Poderes Executivos estadual, distrital e municipal" (BRASIL, 2008, p.1). Ao lidar com os dados geoespaciais dos sítios arqueológicos brasileiros, o CNSA foi afetado pelas novas previsões do Decreto $n^{\circ}$ 6666/2008. Assim, coube ao IPHAN promover as atualizações necessárias para enquadramento na nova normativa.

Em consonância à instituição da INDE, a Comissão Nacional de Cartografia (CONCAR) instituiu o Perfil de Metadados Geoespaciais do Brasil - Perfil MGB. O perfil definiu os atributos de interesse acerca dos dados Geoespaciais, permitindo um maior controle em sua produção, qualidade e usabilidade. Assim, o Brasil optou pelo uso do padrão proposto pela ISO 19.115/2003- Geographic Information-Metadata. O padrão visa: "Identificar o produtor e a responsabilidade técnica de produção; Padronizar a terminologia utilizada; Garantir o compartilhamento e a transferência de dados; Viabilizar a integração de informações; Possibilitar o controle de qualidade; Garantir os requisitos mínimos de disponibilização" (CONCAR, 2009).

Com a instituição da INDE e o do Perfil MGB o Estado brasileiro instituiu um modelo oficial de organização de dados geoespaciais e seus metadados, que deve ser adotado pelas instituições públicas. A adoção deste modelo possibilitou avanços na elaboração de diretrizes nacionais na criação de cadastros territoriais. Dessa forma, o Ministério das Cidades publicou em 2009 a Portaria $n^{\circ} 511$, que estabeleceu as diretrizes técnicas para elaboração de cadastro territorial multifinalitário por parte dos municípios brasileiros. Devido à sua natureza jurídica, a portaria apresentou apenas um caráter orientativo e, portanto, não impositivo na forma da lei aos municípios. O ministério realizou também a publicação um manual de apoio contendo orientações para a aplicação das diretrizes da referida portaria.

A Portaria $n^{\circ}$ 511/2009 apresentou em seu conteúdo uma série de definições legais para os conceitos que compõe o universo dos cadastros territoriais e ainda diversos parâmetros técnicos a serem seguidos pelos municípios ou instituições na construção de seus cadastros. A definição de parâmetros técnicos normatiza uma linguagem comum que irá garantir que todos estes cadastros sigam o mesmo padrão, facilitando a troca de informações entre instituições. Uma importante definição conceitual da portaria consta no artigo $1^{\circ}$, que apresenta a seguinte definição:

O Cadastro Territorial Multifinalitário (CTM), quando adotado pelos Municípios brasileiros, será o inventário territorial oficial e sistemático do município e será embasado no 
levantamento dos limites de cada parcela, que recebe uma identificação numérica inequívoca. Esta parcela é definida como uma parte contígua da superfície terrestre com regime jurídico único (BRASIL, 2009, p.01).

A portaria prevê ainda que estas parcelas territoriais identificadas deverão ser medidas e localizadas por meio de coordenadas geográficas. Além disso, prevê a correlação entre os dados do cadastro territorial com as informações do Registro de Imóveis, que devem constituir o Sistema de Cadastro e Registro Territorial - SICART em cada município brasileiro. Prevê também a necessidade de integração dos dados do cadastro territorial com outros cadastros temáticos, que juntos devem constituir o Sistema de Informações Territoriais - SIT de cada município (BRASIL, 2009).

Sobre os cadastros territoriais temáticos, o manual de apoio publicado pelo Ministério das Cidades os define como cadastros direcionados a temas que geralmente exigem competência específica de pessoal ou instituição especializada. Destaca ainda que, diante da complexidade do território, não existe instituição que possa administrar com competência todos os possíveis cadastros territoriais. O manual destaca também que, no âmbito da informática, os cadastros territoriais multifinalitários e os cadastros territoriais temáticos devem ser construídos sob um sistema único, permitindo o fluxo de informações entre eles (CUNHA; ERBA, 2010).

\section{AS ESPECIFICIDADES DOS SÍTIOS ARQUEOLÓGICOS}

A conceituação teórica sobre os sítios arqueológicos molda-se nos domínios científicos da Arqueologia, disciplina na área das ciências humanas que "tem como objetivo principal de seus estudos a história do homem e suas diversas formas de manifestação social, cultural, artística, reconhecidas e identificadas por meio de remanescentes materiais de culturas extintas" (CORDEIRO, 2006, p. 5). Estuda, portanto, as culturas a partir do seu aspecto material, construindo suas interpretações através da análise dos artefatos, seus arranjos espaciais e sua implantação na paisagem (GASPAR, 2000). Para atingir seus objetivos dispõe de procedimentos teóricos e metodológicos próprios, compreendendo uma série de etapas de pesquisa que devem ser rigorosamente cumpridas para tornar o conhecimento produzido válido (NAJJAR, 2005).

A existência da Arqueologia depende fundamentalmente da possibilidade de análise dos remanescentes produzidos pelas populações pretéritas. Os locais onde são encontrados esses vestígios materiais constituem os sítios arqueológicos. Compõem esses vestígios os artefatos e estruturas produzidas pela humanidade e ainda os chamados ecofatos, isto é, as coisas da natureza que eram utilizadas como conchas, sementes e ossos (MORLEY, 1982).

A partir da análise desses vestígios é possível evidenciar um número muito grande de informações sobre o modo de vida dos povos pretéritos, como seu padrão de distribuição regional, as características dos ambientes que habitavam, os recursos que extraíam e sua organização social. As características sui generis dos sítios arqueológicos os tornam altamente relevantes do ponto de vista científico, tornando-os peça chave no processo de reconstrução da história da sociedade humana no planeta (MORAIS, 1999).

Considerando o fato de que o material arqueológico é limitado, a conservação dos locais onde são encontrados estes artefatos é essencial para a existência da Arqueologia. A disponibilidade de material para estudo permite a sistematização de um número cada vez maior de informações sobre a história da espécie humana. Além disso, o avanço tecnológico e surgimento de técnicas podem proporcionar diferentes abordagens aos estudos, e por isso é fundamental que exista material de estudo preservado ainda in situ (NETTO, 2005). É importante destacar que os sítios arqueológicos podem ser preservados em sua totalidade ou ainda serem objetos de escavação arqueológica. Na segunda opção, os remanescentes materiais podem ser parcialmente ou totalmente resgatados, de acordo com as necessidades de proteção do patrimônio.

Por meio dos estudos do patrimônio arqueológico, pode-se ainda atribuir identidade cultural aos grupos pré-históricos com base em sua localização, tecnologia, restos alimentares, esqueletos e demais vestígios. A partir dessas informações básicas, oriundas dos materiais presentes nos sítios, pode-se alcançar outro nível de informação, mais complexo, relacionado à compreensão sociocultural daqueles grupos. Portanto, de um ponto de vista antropológico a importância dos sítios arqueológicos resulta de sua capacidade de individualizar os diferentes grupos sociais que já habitaram o planeta (NETTO, 2005). 


\section{PROTEÇÃo E GESTÃo do PATRIMÔNIO ARQUEOLÓGICO NACIONAL}

O patrimônio arqueológico começou a ser considerado do ponto de vista jurídico a partir da instituição da Política Cultural Brasileira que se consolidou com a criação do Serviço de Patrimônio Histórico e Artístico Nacional (SPHAN) no ano de 1937 (LIMA, 2001). Inspirada em instituições similares existentes em outros países, a finalidade do SPHAN era "promover em todo país, de modo permanente, o tombamento, a conservação, o enriquecimento e o conhecimento do patrimônio histórico e artístico nacional" (LIMA, 2001, p. 54).

Do ponto de vista dos sítios arqueológico, a institucionalização da Política Cultural Brasileira possibilitou sua proteção por meio do instituto jurídico do tombamento. O tombamento era o único instrumento de proteção existente à época, sendo utilizado também para proteção de outras tipologias de bens culturais como conjuntos arquitetônicos, edifícios, jardins, equipamentos urbanos e as coleções ou acervos com valor histórico (BRASIL, 1937). No entanto, em comparação com outras tipologias de patrimônios materiais os sítios arqueológicos ocorrem em quantidade incomparavelmente maior. A situação é demonstrada pelo fato de que atualmente existem aproximadamente 27 mil sítios arqueológicos registrados no país e apenas cerca de 1.200 tombamentos de bens culturais de outras tipologias (BRASIL, 2020).

A dificuldade de proteção do patrimônio arqueológico do Brasil foi amenizada a partir de 1961 quando foi decretada a Lei n ${ }^{\circ} 3.924 / 61$ que ficou conhecida como "Lei da Arqueologia". Dentre os artigos que compõe a lei, destaca-se o $1^{\circ}$, que previu: "os monumentos arqueológicos ou pré-históricos de qualquer natureza existentes no território nacional e todos os elementos que neles se encontram ficam sob a guarda e proteção do Poder Público (...)" (BRASIL, 1961, p.1).

A "Lei da Arqueologia" alterou profundamente o quadro referente à proteção dos sítios arqueológicos no Brasil. Se anteriormente essa proteção dependia de um processo de tombamento, a nova lei promoveu a salvaguarda de forma ampla e imediata de todos os sítios arqueológicos conhecidos ou que viessem a ser encontrados no país. Essa ampla proteção fazia-se necessária frente aos impactos frequentemente ocasionados por atividades de extração mineral, por obras de infraestrutura em geral, por escavações ilegais e por qualquer outra atividade que envolvesse alterações na superfície terrestre.

Ao tratar sobre o regime jurídico protetivo instituído pela Lei da Arqueologia, Vieira (2011) destaca

a desnecessidade da utilização de um instrumento jurídico específico de tutela como, exempli gratia, o tombamento, o inventário, a desapropriação etc., para que fiquem investidos no regime jurídico especial de proteção, haja vista a determinação constitucional de constituírem aqueles "bens públicos" por natureza, estando assim, desde a sua origem, afetados pelo interesse público da preservação cultural e científica, sendo, portanto, gravados dos atributos de: inalienabilidade, indisponibilidade, impenhorabilidade e não-onerosidade, próprios deste específico regime jurídico (VIEIRA, 2011, p.6).

Os entendimentos jurídicos da Lei da Arqueologia foram incorporados pela Constituição de 1988. A referida Carta Constitucional foi a primeira do Brasil a contemplar elementos referentes ao patrimônio cultural, definindo como obrigação do poder público a promoção de sua proteção. Sendo assim, no caso dos sítios arqueológicos, a Constituição definiu-os no artigo 20 como bens pertencentes à União, sendo sua salvaguarda competência comum a todos os entes federativos. Neste tema destaca-se também o artigo 216, que identifica os bens que constituem o Patrimônio Cultural Brasileiro:

Art. $216^{\circ}$ Constitui patrimônio cultural Brasileiro os bens de natureza material e imaterial, tomados individualmente ou em conjunto, portadores de referência à identidade, à ação, à memória dos diferentes grupos formadores da sociedade Brasileira, nas quais se incluem:

I - as formas de expressão;

II - os modos de criar, fazer e viver;

III - as criações científicas, artísticas e tecnológicas;

IV - as obras, objetos, documentos, edificações e demais espaços destinados a manifestações artístico-culturais;

$\mathrm{V}$ - os conjuntos urbanos e sítios de valor histórico, paisagísticos, artístico, arqueológico, paleontológico, ecológico e científico (BRASIL, 1988, p.116). 
No atual contexto jurídico-institucional, os sítios arqueológicos são compreendidos como bens culturais públicos afetados pelo interesse coletivo de sua preservação, apresentando regime jurídico protetivo diante de sua importância e excepcionalidade. Quando estão localizados em áreas privadas, os sítios arqueológicos constituem locais onde o direito de propriedade só poderá ser exercido em conformidade com a preservação do patrimônio arqueológico de acordo com o parágrafo $1^{\circ}$ do artigo $n^{\circ} 1.228$ do Código Civil. Ou seja, os sítios arqueológicos impõem uma restrição de uso nos locais onde ocorrem. Neste contexto, cabe ressaltar também que Lei $n^{\circ}$ 9605/1998, mais conhecida como Lei de Crimes Ambientais, prevê penas para quem efetue danos ou cause algum tipo de alteração em sítios arqueológicos (VIEIRA, 2011).

Em resumo, do ponto de vista da gestão territorial, os sítios arqueológicos são bens da União, inseridos em regime jurídico protetivo, que impõe limitações de uso em propriedades privadas e cuja preservação é de responsabilidade do poder público em suas três esferas. Como os sítios arqueológicos são bens da União, as ações que envolvem sua identificação e fiscalização são, a priori, responsabilidade do IPHAN, autarquia atualmente vinculada a Secretaria Especial da Cultura do Ministério do Turismo.

No que diz respeito à Arqueologia, o IPHAN tem como uma de suas responsabilidades a emissão de portarias autorizando a execução de pesquisas de caráter arqueológico no território nacional. O instituto atua também na avaliação de estudos de caráter arqueológico realizados como componente do processo de licenciamento ambiental de novos empreendimentos conforme prevê a Portaria $n^{\circ} 230 / 2002$. Neste caso, cabe ao órgão a avaliação dos estudos realizados e a emissão de pareceres técnicos sobre a viabilidade dos empreendimentos propostos (BRASIL, 2002).

Cabe ao IPHAN também o gerenciamento das geoinformações sobre os sítios arqueológicos localizados no território nacional. Conforme citado anteriormente, as pesquisas arqueológicas no Brasil começaram em meados do século XIX. Desde então, diversos novos sítios vêm sendo identificados, gerando novos dados espaciais e alfanuméricos a serem administrados pelo instituto. Diante da demanda constante, a instituição vem se empenhando desde a década de 90 na criação de soluções para gerenciar estes dados.

\section{CADASTRO TERRITORIAL TEMÁTICO DE SÍTIOS ARQUEOLÓGICOS}

O processo de identificação, medição e cadastro de sítios arqueológicos é considerado como parte do procedimento técnico que o poder público dispõe para garantir a salvaguarda destes locais. A importância dessas ações foi destacada na Convenção do Patrimônio Arqueológico, evento ocorrido em Paris em 1972. Ao fim da convenção foi elaborada uma carta de recomendação contendo uma série de definições conceituais e procedimentos técnicos a serem observados pelos países signatários na gestão de seus bens patrimoniais. A carta ressalta a importância da realização de inventários nacionais públicos contendo a localização geográfica dos sítios bem como suas informações arqueológicas. Atendendo tais orientações o IPHAN criou no ano de 1997 o Cadastro Nacional de Sítios Arqueológicos (CNSA). Atualmente, os dados armazenados pelo CNSA estão em processo de migração para uma nova plataforma denominada de Sistema Integrado de Conhecimento e Gestão. Sendo assim, serão apresentadas aqui as especificidades das duas plataformas.

O CNSA foi concebido pelo IPHAN em 1997 como parte do Sistema de Gerenciamento do Patrimônio Arqueológico - SGPA. O objetivo inicial do CNSA foi o de estabelecer os padrões nacionais para o processo de geolocalização e identificação de características dos sítios e coleções arqueológicos bem como da documentação técnica produzida sobre os mesmos. Compreende-se que ao coletar e organizar dados um objeto específico que se materializa no território, e que exige conhecimento técnico específico no processo, o CNSA apresenta as características de um Cadastro Territorial Temático tal qual descreve a Portaria $n^{\circ}$ 511/2009 único diploma brasileiro que versa sobre o tema (BRASIL, 2018).

O CNSA pode ser acessado pelo portal eletrônico do IPHAN e contém motores de busca e filtragem com base no nome do município, no nome do estado, no nome do sítio arqueológico e no nome do responsável pelo registro. Dentre as formas de pesquisa no CNSA apenas a indicação do estado é obrigatória. É possível selecionar ainda a tipologia do sítio com relação a sua referência temporal com três opções: históricos, précoloniais e de contato. Para exemplificar a funcionalidade e ergonomia do sistema, foi realizada uma busca apenas com a seleção do estado de Santa Catarina. O sistema retorna como resultado uma lista indicando a existência de 1.754 cadastros entre um total de 27.582 sítios arqueológicos cadastrados em todo território 
nacional (BRASIL, 2020). Esse número tende a aumentar visto que constantemente são realizadas pesquisas arqueológicas que podem descobrir novos sítios. Neste caso, cabe aos pesquisadores o preenchimento da ficha de cadastro e encaminhamento ao IPHAN.

Nas ocorrências encontradas é possível acessar individualmente a ficha de cadastro de cada sítio. As fichas são compostas por três páginas que congregam um conjunto de dados acerca de cada um dos registros. O conteúdo dessas fichas foi institucionalizado por meio da Portaria $\mathrm{n}^{\circ} 241 / 98$, que em seu teor contempla de forma minudente as instruções para seu preenchimento.

A ficha de cadastro apresenta um nível de agrupamento de itens de acordo com a natureza da informação solicitada. Neste caso, os itens podem ser agrupados em cinco grandes conjuntos. $\mathrm{O}$ primeiro conjunto contém as informações de identificação do sítio, isto é, seu nome, sua sigla de cadastro, o município e UF onde está localizado, uma descrição sumária de suas características e se existem outros sítios relacionados com este, conforme destaca a Figura 1.

Figura 1 - Conjunto de informações de identificação na ficha de cadastro de sítio arqueológico.

\begin{tabular}{|c|c|c|}
\hline $\begin{array}{l}\text { Ministério } \\
\text { da Cultura }\end{array}$ & $\begin{array}{l}\text { Cadastro Nacional de } \\
\text { Sítios Arqueológicos }\end{array}$ & if IPHAN \\
\hline \multirow[t]{2}{*}{ Sistema Nacional de Informaçбes Culturais - SNIC } & CNSA / SGPA* & \multirow[t]{2}{*}{ Centro Nacional de Arqueologia - CNA } \\
\hline & - CNSA SC00278 - & \\
\hline \multicolumn{3}{|l|}{ Nome do sítio: Estação Florestal I } \\
\hline Outras designações e siglas: FLN 001. & & CNSA: $\mathrm{SC00278}$ \\
\hline Município: Florianópolis & & UF: SC \\
\hline
\end{tabular}

Fonte: Brasil (2020).

O segundo conjunto refere-se aos dados geométricos do sítio arqueológico, ou seja, seu comprimento, largura, altura e área, como pode se observar na Figura 2. É fundamental destacar que, embora exista um campo para preenchimento de coordenadas na ficha de registro, essa informação não é divulgada no acesso público do CNSA. Dessa forma, no preenchimento da ficha é necessário indicar a técnica utilizada para realização da medição, se estimada, com passos, por meio de mapas ou com instrumentos. Neste caso, a portaria $\mathrm{n}^{\circ}$ 241/98 prevê que os limites devem ser indicados por "pontos referenciais no sistema de coordenadas UTM (Universal Transversa de Mercator) com precisão de metros (...)" (BRASIL, 1988, p.47). A portaria orienta ainda que seja informado o Datum utilizado no equipamento GNSS para obtenção das coordenadas e a margem de erro métrico da leitura dos pontos. Por fim, completam o conjunto de informações a unidade geomorfológica, a compartimentação topográfica, a altitude, o nome do rio mais próximo e a bacia hidrográfica em que o sítio arqueológico está inserido.

Figura 2 - Conjunto de informações geométricas na ficha de cadastro de sítio arqueológico.

\begin{tabular}{|c|c|c|c|}
\hline \multirow{2}{*}{ Comprimento: $0 \mathrm{~m}$} & Largura: $0 \mathrm{~m}$ & \multirow{2}{*}{$\begin{array}{c}\text { Altura máxima: 0m } \\
\text { Passo }\end{array}$} & (a partir do nivel do solo) \\
\hline & Estimada & & Instrumento \\
\hline \multicolumn{4}{|c|}{ Unidade geomorfológica: Planície } \\
\hline \multicolumn{4}{|c|}{ Compartimento topográfico: Planície litorânea } \\
\hline \multicolumn{4}{|c|}{ Altitude: $0 \mathbf{m}$ (com relação ao nivel do mar) } \\
\hline \multicolumn{4}{|l|}{ Água mais próxima: } \\
\hline \multicolumn{4}{|l|}{ Distância: 0m } \\
\hline Rio: & & & \\
\hline Bacia: Cubatão do S & Sul & & \\
\hline
\end{tabular}

Fonte: Brasil (2020).

O terceiro conjunto de informações da ficha de cadastro do CNSA refere-se à realidade físicogeográfica e territorial do local onde está inserido o sítio arqueológico, conforme demonstra a Figura 3. Compõe este conjunto os dados sobre a tipologia vegetal, o uso atual do terreno, a tipologia de propriedade da 
terra e a eventual incidência de proteção ambiental legal na área.

Figura 3 - Conjunto de informações físico-geográficas na ficha de cadastro de sítio arqueológico.



O quarto conjunto é o que congrega dados referentes às características arqueológicas do sítio e por este motivo apresenta um maior número de campos a serem preenchidos quando comparado aos outros conjuntos de dados, conforme evidenciam as Figuras 4 e 5. Compõe este conjunto a categoria histórica do sítio, seu grau de exposição, o contexto de deposição, sua tipologia, a forma e tipo de solo e ainda a descrição de sua estratigrafia, estruturas, artefatos e demais vestígios encontrados e sua filiação cultural. Compõe ainda o conjunto as informações referentes a eventuais datações realizadas, ao grau de integridade e fatores de destruição do sítio, sua relevância para preservação e quais atividades de pesquisa foram desenvolvidas no local.

Figura 4 - Conjunto de informações arqueológicas na ficha de cadastro de sítio arqueológico.

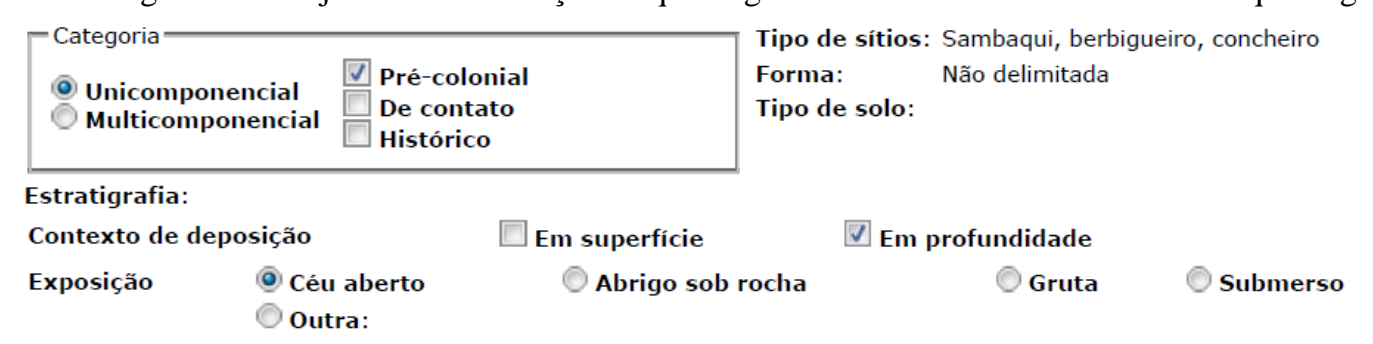

Fonte: Brasil (2020). 
Figura 5 - Conjunto de informações arqueológicas na ficha de cadastro de sítio arqueológico.

$\begin{array}{|ll|}\square \text { Estrutura } & \square \text { Canais tipo trincheiras, } \\ \text { valetas }\end{array}$

$\square$ Aítico lascado $\quad \square$ Cerâmico
$\square$ Lítico polido $\quad \square$ Sobre concha
$\square$ Sobre material orgânico
Outros vestígios líticos:

Material histórico:

Outros vestígios orgânicos: restos alimentares faunísitcos.

Outros vestígios inorgânicos:

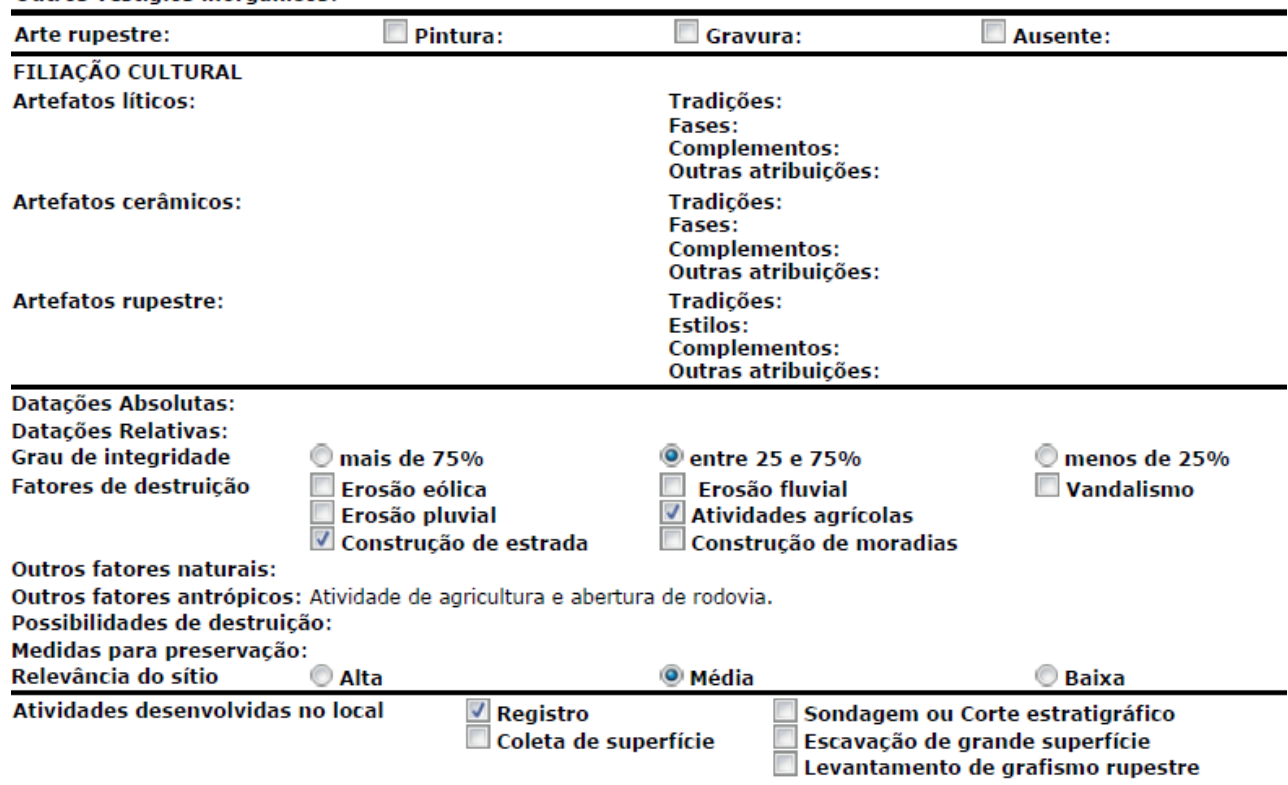

Nome do responsável pelo registro: FOSSARI, Teresa \& BASTOS, Rossano.

Data do registro: 30/12/1899 Ano do registro: 1987

Fonte: Brasil (2020).

Por último, o quinto conjunto de informações refere às questões de ordem administrativas e burocráticas, contendo o nome do responsável pelo registro e a data de sua realização, o nome do projeto de pesquisa e a documentação técnica produzida, conforme pode ser observado na Figura 6.

Figura 6 - Conjunto de informações administrativas na ficha de cadastro de sítio arqueológico.

Nome do projeto:

\begin{tabular}{|c|c|c|}
\hline \\
\hline $\begin{array}{l}\text { Documentação produzida (quantidade) } \\
\qquad \text { Mapa com sítio plotado: } 0\end{array}$ & 0 & Foto preto e branco: 0 \\
\hline Croqui: & 0 & Reprografia de imagem: 0 \\
\hline Planta baixa do sítio: & 0 & Imagem de satélite: 0 \\
\hline Planta baixa dos locais afetados: & 0 & Cópia total de arte rupestre: 0 \\
\hline Planta baixa de estruturas: & 0 & Cópia parcial de arte rupestre: 0 \\
\hline Perfil estratigráfico: & 0 & Ilustração do material: 0 \\
\hline Perfil topográfico: & 0 & Caderneta de campo: 0 \\
\hline Foto aérea: & 0 & Video / Filme: 0 \\
\hline Foto colorida: & 0 & Outra: 0 \\
\hline
\end{tabular}

Bibliografia

DUARTE, G. Anais do Museu da UFSC, 1971.

Outra: 0

Responsável pelo preenchimento da ficha: Rossano Lopes Bastos

Fonte: Brasil (2020).

Conforme apresentado, as fichas de cadastro do CNSA contemplam um número considerável de dados 
descritivos. Analisando as informações contempladas pela ótica dos cadastros territoriais definidas pela FIG (1995), há alguns apontamentos que merecem destaque.

Primeiramente, é importante destacar que a portaria $n^{\circ} 241 / 98$, que baliza o cadastramento de sítios arqueológicos, prevê apenas que as coordenadas de sua localização apresentem "precisão de metros". Além disso, prevê a possibilidade de medições estimadas por meio da contagem de passos ou ainda com uso de cartas topográficas, sem especificar a escala mínima aceitável para obtenção dos valores de coordenadas. Diante dessas orientações, é possível que sítios arqueológicos sejam cadastrados com erro posicional (BRASIL, 1998). Considerando que estes dados podem (e devem) ser utilizados como base em diversos processo de gestão e planejamento territorial, as inconsistências das informações de sua localização geram um quadro de insegurança jurídica sobre o tema. Dificulta-se, dessa maneira, que o poder público cumpra seus deveres institucionais de promover a proteção do patrimônio arqueológico.

Outro ponto importante sobre o CNSA é que seu banco de dados não é geográfico. As informações referentes às localizações dos sítios arqueológicos são tratadas como meros atributos numéricos e não como informações primitivas do conjunto de dados. Além disso, seu banco de dados estrutura-se a partir de uma lógica específica, dificultando ou inviabilizando um possível fluxo para bancos de dados geográficos de outras instituições.

Essas pequenas fragilidades levantam inclusive o questionamento se o CNSA consiste, de fato, em um cadastro territorial temático. Por um lado, os dados referem-se a um elemento material do território, que apresenta um regime jurídico específico e cuja organização exige expertise de instituição específica, características típicas de um cadastro territorial temático. Por outro lado, o conceito de cadastro territorial, conforme define a FIG (1995) carrega em sua essência a medição precisa dos limites das parcelas que compõe um determinado território.

Frente ao impasse, defende-se a ideia de que o CNSA, ainda que contenha as fragilidades citadas, caracteriza-se como um cadastro territorial temático. A ausência de parâmetros cadastrais geoespaciais mais claros é reflexo, sobretudo, da falta de cultura cadastral no país. Essa falta de cultura afeta até mesmo os cadastros de bens imobiliários que frequentemente tem problemas nos dados de localização destes elementos. Diante desse contexto, é quase natural que um cadastro territorial direcionado aos sítios arqueológicos acabe reproduzindo essa lógica.

Conforme já mencionado neste trabalho, a estruturação da INDE e do Perfil MGB gerou uma necessidade de modernização dos processos de criação e armazenamento de dados geoespaciais em instituições brasileiras como o IPHAN. Assim, objetivando adequar-se à nova realidade o IPHAN começou a desenvolver em 2013 a plataforma denominada Sistema de Integrado de Gestão e Conhecimento - SICG estruturado com base nas prerrogativas da INDE e do Perfil MGB (IPHAN, 2020). Atualmente, a plataforma encontra-se ativa e funcional, podendo ser acessada pelo portal eletrônico do IPHAN.

O SICG caracteriza-se como o primeiro sistema do órgão a utilizar os preceitos da inteligência geográfica para cadastramento, consulta e difusão dos dados referente ao patrimônio cultural brasileiro. Assim, o sistema busca estreitar a interação entre o IPHAN e demais entes interessados dos bens culturais, visto que proporciona em uma única interface, o cadastro de bens diversos que, historicamente, encontravam-se de forma isolada e sem comunicação. Outro ponto é a articulação, no território, do cadastro dos bens culturais materiais e imateriais, fato inédito na Instituição, o que permite um olhar diferenciado para a identificação, reconhecimento e gestão dos bens culturais (IPHAN, 2020).

O referido sistema apresenta ainda um papel federativo uma vez que permite "o compartilhamento do cadastro de bens considerados como patrimônio cultural por prefeituras e governos locais". Com isso, buscase um "ganho de escala territorial e amplitude temática do alcance das políticas públicas de reconhecimento/proteção dos bens culturais". O objetivo final do SICG é o de construir uma base de dados estruturada e organizada por categorias de bens culturais, contando com a colaboração dos governos locais, das universidades e outras instituições envolvidas com o tema. Com a consolidação de um banco de dados amplo, torna-se possível a realização de análises espaciais mais complexas, que possam direta ou indiretamente salvaguardar o patrimônio cultural como um todo (IPHAN, 2020).

Por fim, uma importante característica do SICG consiste na capacidade de representação da localização 
dos bens culturais cadastrados na plataforma sob uma base cartográfica, conforme mostra a Figura 6. Assim, é possível clicar sob os bens representados e acessar suas informações alfanuméricas. Há ainda, na parte superior, um menu para realização de busca por palavra-chave ou ainda realização de busca avançada com base nas características dos bens culturais, conforme também pode ser observado da Figura 7.

Figura 7 - Tela referente aos bens culturais brasileiros no SICG.

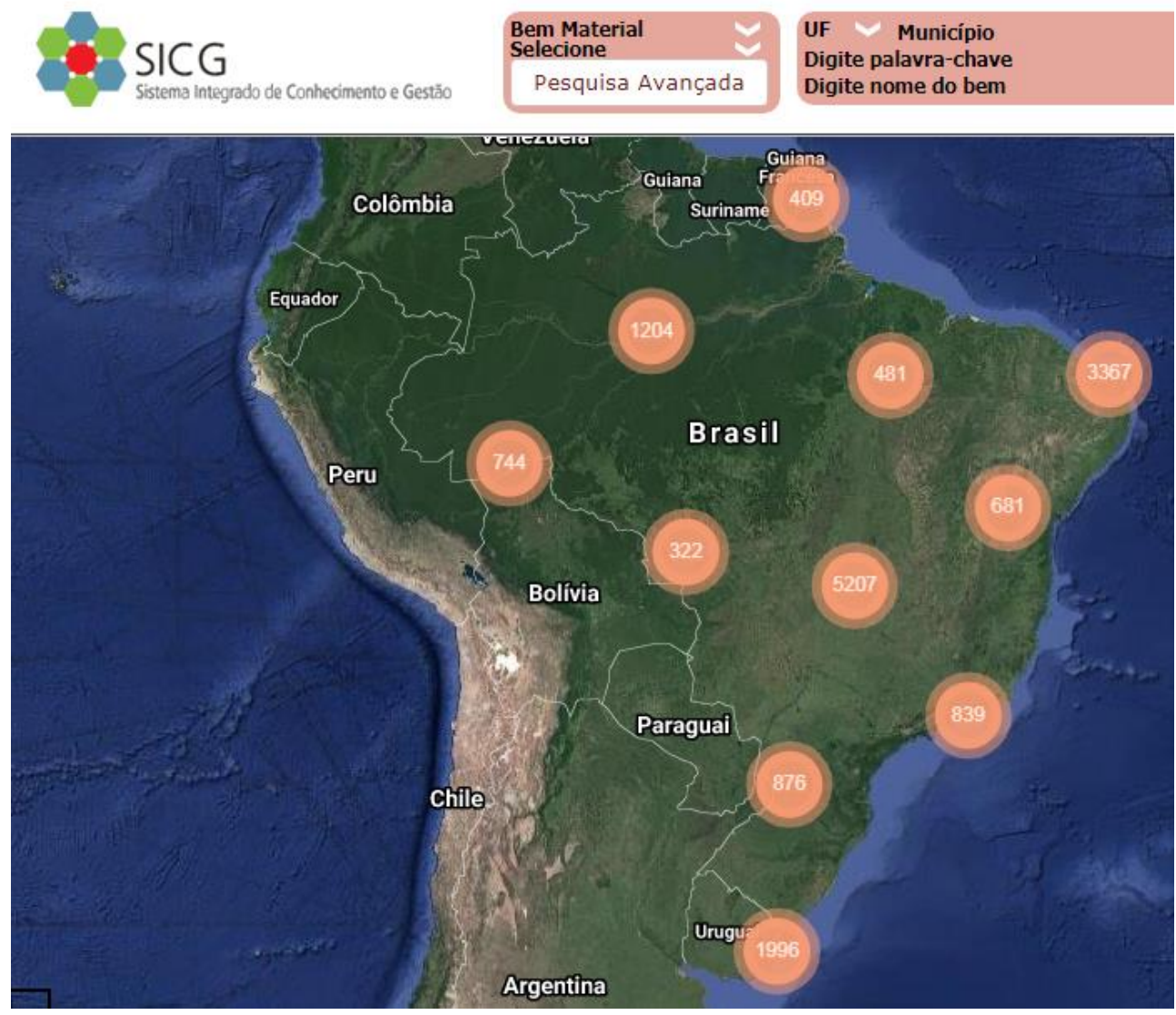

Fonte: Brasil (2020).

No que diz respeito ao CNSA, seus dados passaram a ser incorporados ao banco de dados do SICG, permitindo buscas a partir da base cartográfica. O sistema facilita também o processo de cadastro de novos sítios arqueológicos visto que possibilita o preenchimento de fichas de registro de maneira online, permitindo ainda o envio de um arquivo do tipo shapefile devidamente georreferenciado para localizar o sítio a ser cadastrado. No entanto, é fundamental destacar que enquanto o banco de dados do CNSA acusa aproximadamente 27 mil registros, o do SICG indica apenas 16 mil. Embora não tenham sido encontradas informações concretas, depreende-se que essa defasagem resulta de um processo ainda em andamento de transferência de dados entre as plataformas.

Como o SICG mostra os dados cadastrais dos sítios arqueológicos sobre uma base cartográfica, as fragilidades referentes à acurácia de sua localização podem ser observadas com facilidade. Dessa forma, a Figura 8 representa tal situação ao representar o sítio arqueológico Ilha do Campeche (ponto azul) em posição distinta à da ilha, localizada a sudeste do ponto representado. 
Figura 8 - Erro posicional na representação espacial do Sítio Arqueológico Ilha do Campeche, em Florianópolis, SC.

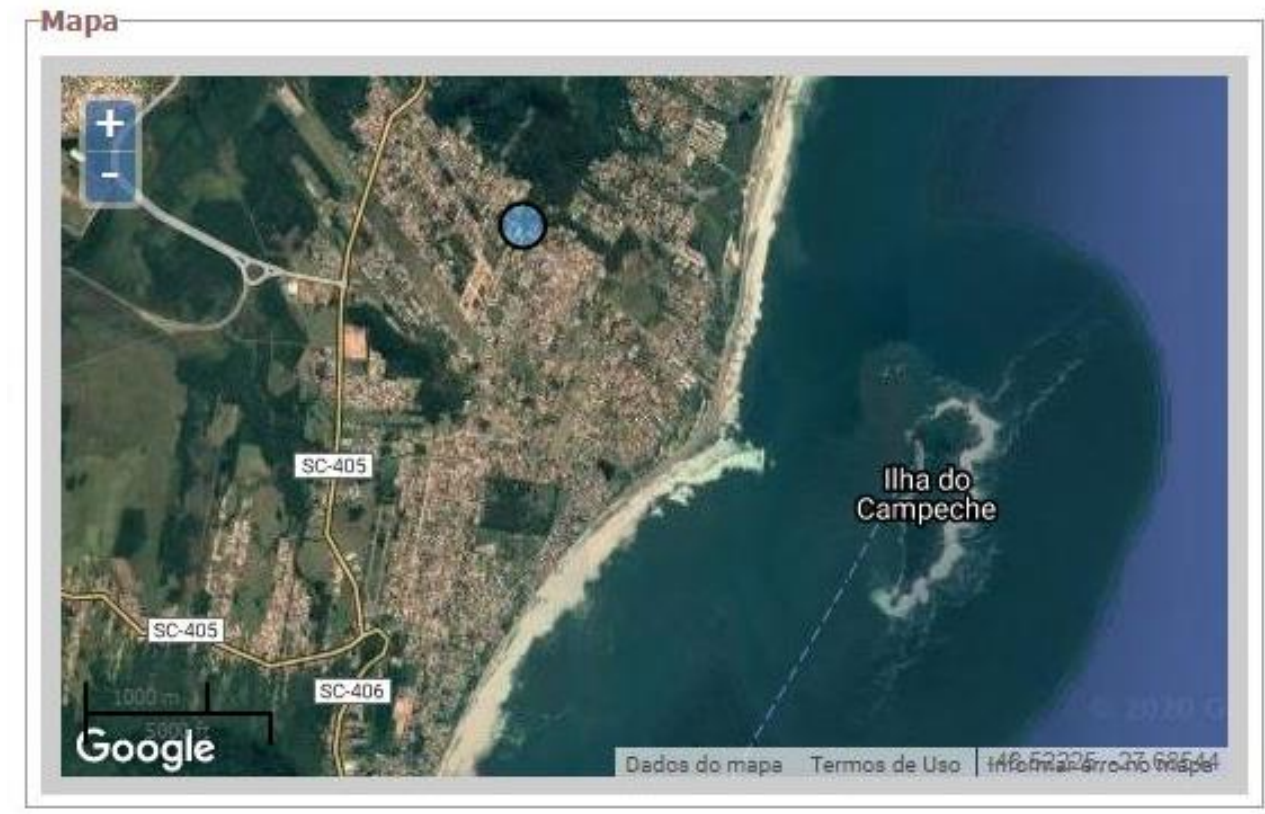

Fonte: Brasil (2020).

A inconsistência apontada na Figura 8 é apenas um exemplo que provavelmente se repete em outras situações. A identificação da totalidade de inconsistências nos dados espaciais dos sítios arqueológicos cadastrados no país não é um dos objetivos do presente artigo, sendo, portanto uma mera demonstração dos problemas relativos a ausência de rigor na medição da localização dos bens culturais protegidos.

Em 2018 uma nova portaria promoveu avanços no processo de inclusão de dados no SICG. Trata-se da Portaria $n^{\text {o }} 375 / 18$ que instituiu a política de patrimônio cultural material do IPHAN. No que tange aos sítios arqueológicos, a portaria determinou no artigo 75 que o reconhecimento oficial de sua existência ocorre por meio da homologação de seu cadastro no SICG. O referido artigo definiu ainda, no parágrafo $2^{\circ}$ que o cadastro de sítios arqueológicos no âmbito do SICG equipara-se ao Cadastro Nacional de Sítios Arqueológico - CNSA ou ao Cadastro dos Monumentos Arqueológicos do Brasil mencionado no artigo 27 da Lei n 3.924 , de 26 de julho de 1961. Por fim, o artigo previu por meio do parágrafo $3^{\circ}$ que uma nova portaria deveria ser publicada estabelecendo os critérios e procedimentos para a homologação de sítios arqueológicos pelo IPHAN (BRASIL, 2018).

Em consonância com as prerrogativas da Portaria no 375/2018, o IPHAN realizou em 2019 a publicação da Portaria no 316 que estabeleceu "os procedimentos para a identifícação e o reconhecimento de sítios arqueológicos pelo Iphan". Dessa forma, a portaria indicou no artigo $3^{\circ}$ que "o processo de identificação de sítio arqueológico, quando da sua localização, consiste em sua delimitação, georreferenciamento, caracterização e contextualização" (BRASIL, 2019, p. 1). Nesse sentido, o artigo $4^{\circ}$ definiu que o processo de delimitação consiste na obtenção dos limites horizontais do sítio arqueológico, de forma que se crie um polígono. De forma complementar, o artigo $5^{\circ}$ determina que os polígonos devam estar vinculados ao Sistema Geodésico Brasileiro, definindo em parágrafo único que “deverão ser utilizadas coordenadas geográficas em graus decimais e Datum Sirgas 2000" (BRASIL, 2019, p. 1). Apesar das orientações dos artigos $4^{\circ}$ e $5^{\circ}$, a Portaria n $316 / 2019$ não faz menção a parâmetros mínimos de precisão com relação ao georreferenciamento dos sítios arqueológicos.

Ainda no âmbito da Portaria no 316/2019 merece destaque o artigo $8^{\circ}$ que define que o reconhecimento oficial dos sítios arqueológicos fica condicionado à aprovação das informações prestadas durante o processo de cadastro. Por fim, o artigo $9^{\circ}$ elenca os aspectos a serem analisados pelo IPHAN para aprovação do cadastro. Dentre estes aspectos estão a coerência entre os dados das documentações apresentadas e dos dados inseridos no cadastro, a completude desses dados e a acurácia no georreferenciamento e na delimitação. Não há, no entanto, indicação de formas de avalição dessa acurácia. 


\section{CONCLUSÕES}

O Estado brasileiro assumiu o compromisso legal de manutenção de um cadastro de sítios arqueológicos a partir da instituição da Lei da Arqueologia em 1961. No entanto, a sistematização dos dados destes objetos teve início apenas em 1997 com a criação do Cadastro Nacional de Sítios Arqueológicos CNSA. Os procedimentos e dados a serem inseridos neste cadastro foram definidos por meio da Portaria $\mathrm{n}^{\mathrm{o}}$ 241/98. Assim, a ficha de registro deveria ser preenchida pelo pesquisador que identificou um novo sítio arqueológico e posteriormente encaminhada ao IPHAN para inclusão dos dados no CNSA. Estas fichas de registro, por sua vez, podem ser acessadas pelo sítio eletrônico do CNSA, que atualmente apresenta cerca de 27 mil sítios cadastrados.

Analisando a estrutura do CNSA pela ótica da Cartografia Cadastral, verifica-se que este não atende as premissas técnicas e teóricas definidas pela FIG (1998) no âmbito conceitual dos cadastros territoriais. Tal fato decorre da inexistência de parametrização na precisão na medição das coordenadas de localização dos sítios arqueológicos, gerando incertezas com relação à sua real espacialidade. Como consequência, cria-se um quadro marcado pela insegurança jurídica em processos que envolvam a tomada de decisão sobre os sítios arqueológicos no âmbito da gestão do território. Além disso, o CNSA não utiliza um banco de dados geográficos, sendo as informações espaciais consideradas como meros atributos numéricos do cadastro. Com Por esse motivo, existiam dificuldades para a integração dos dados do CNSA com os cadastros territoriais elaborados pelos municípios, tornando mais difícil o cumprimento das prerrogativas legais de proteção dos sítios arqueológicos.

Parte dessas dificuldades foi superada a partir da implantação do Sistema de Informação Conhecimento e Gestão - SICG, que utiliza inteligência geográfica para cadastramento, consulta e difusão dos dados referente ao patrimônio cultural brasileiro. A organização de dados do SICG atende aos requisitos da INDE e do Perfil de Metadados Geoespaciais do Brasil. Essa forma de organização facilita a troca de dados com outras instituições públicas, podendo potencializar a realização de ações no sentido de promoção da proteção dos bens culturais protegidos como os sítios arqueológicos.

No que tange ao CNSA, seus dados têm sido absorvidos gradativamente pelo SICG que apresenta atualmente cerca de 16 mil registros de sítios arqueológicos. Estes registros são representados no sistema sob uma base cartográfica, permitindo o acesso às informações alfanuméricas do cadastro a partir de um clique. $\mathrm{O}$ processo de cadastramento de sítios arqueológicos também foi atualizado, passando a ser realizado diretamente no SICG. Os dados inseridos serão analisados pelo IPHAN que procederá ou não sua homologação. Embora tenha havido atualização na forma de armazenamento dos dados, no preenchimento da ficha e no acesso aos registros dos sítios arqueológicos brasileiros, não houve nenhum tipo de alteração com relação a precisão mínima dos dados referentes à sua localização. Assim, a única orientação existente nesse sentido determina genericamente que a medição apresente "precisão de metros".

Ante o exposto, embora tenham ocorrido avanços significativos, defende-se a necessidade de ampliação da compreensão da importância do cadastro territorial temático de sítios arqueológicos para além da Arqueologia. Dessa forma, é preciso que sejam incorporadas nas práticas de medição de sítios arqueológicos o rigor necessário para que os dados coletados possam integrar-se em sistemas de informações territoriais mais complexos que podem potencializar as ações de promoção da preservação dos sítios arqueológicos por parte do poder público.

\section{Agradecimentos}

Os autores agradecem a CAPES (Coordenadoria de Aperfeiçoamento Pessoal de Ensino Superior) pelo fomento de bolsa de doutorado recebida pelo autor principal (Processo 88882.447443/2019-01).

\section{Contribuição dos Autores}

Os autores realizaram de forma conjunta as etapas de conceptualização e metodologia. O autor Guilherme Linheira realizou a investigação, a redação inicial e a edição, enquanto o autor Francisco Henrique 
de Oliveira realizou a supervisão e revisão do manuscrito.

\section{Conflitos de Interesse}

Os autores declaram que não há conflitos de interesse.

\section{Referências}

BRASIL. Constituição (1988). Constituição da República Federativa do Brasil de 1988. Brasília, DF: Senado Federal: 1988.

BRASIL. Decreto-lei n ${ }^{\circ}$ 25, de 30 de novembro de 1937. Organiza a proteção do patrimônio histórico e artístico nacional. Diário Oficial da União, Rio de Janeiro, RJ, 30 nov. 1937. Seção I, p. 24056.

BRASIL. Lei no 3.924, de 26 de julho de 1961. Dispõe sobre os monumentos arqueológicos e pré-históricos. Diário Oficial da União, Brasília, DF, 26 jul. 1961. Seção I, p. 6793. Brasília, DF, 26 jul. 1961.

BRASIL. Ministério da Cultura. Portaria ${ }^{\circ}$ 241, de 19 de novembro de 1998. Diário Oficial da União, Brasília, DF, n. 228, 27 nov. 1998. Seção 1, p. 47 - 48.

BRASIL. Ministério da Cultura. Portaria ${ }^{\circ} 230$, de 17 de dezembro de 2002. Compatibiliza as fases de trabalho dos licenciamentos ambientais com os estudos preventivos de arqueologia. Diário Oficial da União, Brasília, DF, n. 244, 18 dez 2002. Seção 1, p. 1 - 3.

BRASIL. Ministério das Cidades. Portaria no 511 de 07 de dezembro de 2009. Diretrizes para a criação, instituição e atualização do Cadastro Territorial Multifinalitário (CTM) nos municípios brasileiros. Diário Oficial da União, Brasília, DF, n.234, 08 dez. 2009. Seção 1, p. 75.

BRASIL. Portaria no 375, de 19 de setembro de 2018. Institui a Política de Patrimônio Cultural Material do Iphan e dá outras providências. Diário Oficial da União, Brasília, DF, n. 182, 20 set. 2018. Seção 1, p. 7 - 11.

BRASIL. Portaria n ${ }^{\circ} 316$, de 04 de novembro de 2019. Estabelece Os Procedimentos Para A Identificação e O Reconhecimento de Sítios Arqueológicos Pelo Iphan. Diário Oficial da União, Brasília, DF, n. 214, 04 nov. 2019. Seção 1, p. 25

BRASIL. INSTITUTO DO PATRIMÔNIO HISTÓRICO E ARTÍSTICO NACIONAL. Cadastro Nacional de Sítios Arqueológicos. Disponível em: http://portal.iphan.gov.br/sgpa/?consulta=cnsa. Acesso em: 11 jan. 2020a.

BRASIL. INSTITUTO DO PATRIMÔNIO HISTÓRICO E ARTÍSTICO NACIONAL. Sistema Integrado de Conhecimento e Gestão. Disponível em: https://sicg.iphan.gov.br/. Acesso em: 11 jan. 2020b.

COMISSÃO NACIONAL DE CARTOGRAFIA (CONCAR). Perfil de Metadados Geoespaciais do Brasil (Perfil MGB): Brasília: IBGE, 2009.

CORDEIRO, D. P. Conhecendo arqueologia. Itajaí: Ed. do autor, 2006.

CUNHA, E.M.P; ERBA, D.A. Manual de Apoio - CTM: Diretrizes para a criação, instituição e atualização do cadastro territorial multifinalitário nos municípios brasileiros. Brasília: Ministério das Cidades, 2010.

FÉDÉRATION INTERNATIONALE DES GÉOMÈTRES (FIG). Statement on the cadastre. Canberra: FIG publications, 1995.

GASPAR, M. Sambaqui: arqueologia do litoral Brasileiro. Rio de Janeiro: Zahar, 2000.

KALFMANN, J.; STEUDLER, D. Cadastre 2014. Berna: FIG, 1998.

LIMA, T.A. A proteção do patrimônio arqueológico no Brasil: omissões, conflitos, resistências. Revista de Arqueologia Americana, n. 20, p. 51, 2001.

LOCH, C. Cadastro territorial multifinalitário e gestão territorial. In: $29^{\circ}$ CONGRESSO BRASILEIRO DE EDUCAÇÃO EM ENGENHARIA, 2001, Porto Alegre. Anais... Porto Alegre: Abenge, 2001. p. 63 - 71.

MARTINELLI, M.; GRAÇA, A. J. S. Cartografia Temática: Uma breve história repleta de inovações. Revista 
Brasileira de Cartografia, Rio de Janeiro, v. 4, n. 67, p.913-928, jan. 2015.

MORAIS, J.L.A. Arqueologia e o fator geo. Revista do Museu de Arqueologia e Etnologia, São Paulo, n. 9, p.3-22, dez. 1999.

MORLEY, E. J. O Presente do Passado: O Que é Arqueologia. Florianópolis: Ed. do autor, 1982.

NAJJAR, Rosana. Manual de Arqueologia Histórica. Brasília: IPHAN, 2005.

NETTO, C. A preservação do patrimônio arqueológico: A interseção com o meio ambiente e identidade cultural. Revista do Instituto Goiano de Pré-história e Antropologia. Goiânia, v. 3, n. 1, p. 145-169, jan.jun. 2005.

VIEIRA, J. Patrimônio Cultural Arqueológico e Museus. Revista da AGU, v. 110, p. 01-18, 2011.

\section{Biografia do autor principal}

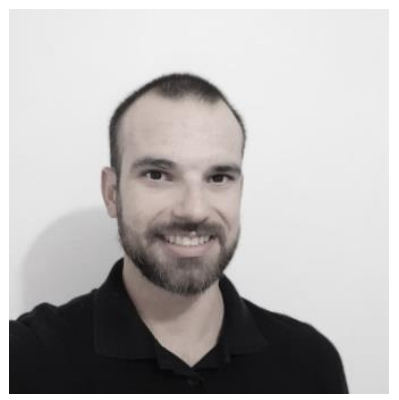

Guilherme Linheira nasceu em 1986 no município de Tubarão, SC. Possui graduação em Geografia pela UFSC e mestrado em Planejamento Territorial e Desenvolvimento Socioambiental pela UDESC. Possui experiência em pesquisas e consultorias técnicas nas áreas de Cartografia, Geoprocessamento e Patrimônio Cultural. Atualmente é doutorando no Programa de Pós-Graduação em Planejamento Territorial e Desenvolvimento Socioambiental da Universidade do Estado de Santa Catarina (UDESC), onde atua também como professor colaborador no Departamento de Geografia. 